\title{
Las obras públicas malagueñas en el siglo XVIII
}

\author{
Francisco R. Cabrera Pablos*
}

\section{INTRODUCCIÓN}

El estudio de los fondos documentales del Archivo Municipal de Málaga en el período objeto de nuestro análisis, especialmente de las noticias contenidas en las Actas Capitulares, nos permiten evaluar con bastante precisión la evolución en esta ciudad de un capítulo tan importante para la economía regional y la propia vida de los habitantes como era el de la evolución de sus obras públicas.

También en la Colección de Originales aparecen un buen número de instrucciones reales que bajo diferentes formas y procedimientos llegaron a Málaga a lo largo de la centuria. Por lo tanto, ambas colecciones constituyen una fuente inagotable de información sobre las preocupaciones locales en ese campo y de las disposiciones que se adoptaron en esta materia ${ }^{1}$.

Tras su análisis, podemos concluir que la obra pública de más envergadura que tuvo lugar en esta ciudad durante la Modernidad fue sin duda alguna la continuación del puerto malagueño, por los altísimos caudales que se emplearon - tanto del Ayuntamiento e instituciones locales como del propio Estado-, y por el elevado número de ingenieros militares que plasmaron en otros tantos proyectos la mágica solución que demandaban los problemas presentados por las instalaciones, sobre todo la tradicional falta de profundidad en el interior del recinto.

\footnotetext{
* Universidad de Málaga.

Es evidente que la documentación municipal no se limita a las colecciones mencionadas. Otras de singular trascendencia son los Libros de Provisiones y los de Protocolos de Secretaría y Escribanía de Cabildo que completan a las anteriores, además de los numerosos legajos cuya consulta resulta obligada en un estudio medianamente detenido de las obras públicas locales, pero cuya sola mención alargaría considerablemente este trabajo.
} 
Del mismo modo, las dificultades que ocasionó el río Guadalmedina a lo largo de nuestra historia, con sus periódicos desbordamientos, generó una amplísima documentación oficial y una relación epistolar con la Corte, en un interesado intento de lograr lo que los malagueños de todos los tiempos deseaban: esto es, acabar con las temidas y trágicas inundaciones de nuestro aprendiz de río.

El abastecimiento de agua fue otro de los problemas con el que se enfrentó este Ayuntamiento a lo largo de los siglos, ya que la ciudad malacitana era deficitaria en tan importante elemento y cuantas gestiones acometieron nuestro ediles en el pasado terminaron fracasando, salvo contadas excepciones.

Así, los crecidos caudales que se emplearon en el manantial conocido como Fuente del Rey cerca de Churriana, no sirvieron de mucho al verse detenidas sus obras después de años de trabajo y cuando el proyecto estaba a medio concluir. Sin embargo, en las últimas décadas del Dieciocho, gracias al interés del obispo malagueño Molina Lario se construyó un acueducto que desde los yacimientos del Guadalmedina acercara tan apreciado elemento a los sedientos ciudadanos.

La evolución de las comunicaciones en esta ciudad supuso también un capítulo de enorme trascendencia para el desarrollo del comercio en todo el hinterland, del que quizás el proyecto más destacado fue el nuevo trazado a la localidad de Antequera por los Montes de Málaga en el llamado camino del Colmenar. Además, los sucesivos estudios sobre la vía que unía nuestra localidad con la de Vélez fueron igualmente importantes por las connotaciones comerciales que dicho mantenimiento implicaba.

Por otra parte, el desarrollo demográfico a lo largo del Dieciocho propició un crecimiento urbano especialmente intenso a partir de su tercera década, del que no podemos ocuparnos por falta de espacio. La utilización del antiguo foso de la ciudad mediante arcadas y las cuantiosas licencias que pedidas por particulares pretendían construir más allá del cinturón murado dan fe de ello. Las playas de San Andrés, zona de la Trinidad y Capuchinos y la urbanización que se realizó en la Caleta en tiempos de Carlos III son los puntos expansivos más importantes.

El análisis de tales cuestiones exige un detenido estudio de la documentación municipal mencionada que, sin duda, se completa con otros archivos locales y con los expedientes que enviados a la Corte por el Ayuntamiento de Málaga aún se conservan a nivel nacional ${ }^{2}$.

Entre los locales destacan, además del Archivo Municipal ya citado, el Archivo Catedral 
Por otra parte, el siglo xvıII asistió a una consolidación técnica del cuerpo de ingenieros militares de singular trascendencia, en cierta medida debido a Jorge Próspero Verbom, nombrado Ingeniero General por Felipe $V$ y que participó activamente en las obras públicas hispanas en general y malagueñas en particular, redactando varios proyectos referidos a la continuación de las obras portuarias y al desvío del río Guadalmedina al norte de la ciudad, llevándole a desembocar en las playas de San Andrés ${ }^{3}$.

La misma ciencia cartográfica alcanzó ya en esta centuria una precisión técnica muy superior a la que había tenido en períodos precedentes, existiendo en archivos internacionales, nacionales y locales una riquísima provisión de fondos sobre Málaga, de imprescindible consulta para comprender el desarrollo urbanístico de nuestra ciudad durante la Edad Moderna ${ }^{4}$.

\section{EL PUERTO}

Es un hecho absolutamente indiscutible que la prosperidad de Málaga a lo largo de la historia ha estado motivada en gran medida por el desarrollo del comercio, y que éste ha dependido en su mayor parte del tráfico portuario, verdadero motor de la vida de la ciudad y de la economía de sus habitantes.

Desde los tiempos más remotos, esta marina se dotó de unas instalaciones precarias al principio pero que fueron consolidándose con el paso de los años. La presencia de una activa economía junto a la imperiosa necesidad que tenía la Corona de contar con un fondeadero capaz de albergar a las naves de su Armada propiciaron la construcción de un

\footnotetext{
y el de la Junta del Puerto. Por otra parte, la propia naturaleza de estas obras obligaba, como decimos, a informar a la Corte de los proyectos más importantes, razón por la cual aparecen a nivel nacional importantes documentos en los que no nos detendremos. Remitimos al Archivo General de Simancas, Servicio Histórico Militar, Archivo Histórico Nacional, Servicio Geográfico del Ejército y Archivo General Militar de Segovia para completar este estudio.

3 Entre 1721 y 1729 aparecen diferentes noticias relativas a la estancia del marqués de Verbom en nuestra ciudad y de los numerosos litigios que sostuvo con el Ayuntamiento con el que sus relaciones no fueron nunca demasiado cordiales, sobre todo en lo referente a nuevas construcciones particulares en la fachada sur malagueña próxima al puerto en detrimento del terreno que precisaban las faenas portuarias. Véase CABRERA PABLOS, F. R., "Construcción de la capilla del puerto malagueño en el siglo Xvilı, Jábega, núm. 44 (1983), págs. 51-61.

Olmedo Checa, M., "Málaga, protagonista de su imagen: lectura cartográfica de cuatro siglos de historia”, en Patrimonio Artístico y Monumental. Málaga, Ed. Ayuntamiento de Málaga, 1990, 249-269.
} 
puerto que era en su momento el más importante del sur del Mediterráneo y uno de los más tráfico en todo el país ${ }^{5}$.

Estas dos cuestiones comercial y militar fueron pues las que impulsaron a Felipe II a autorizar una demanda largo tiempo esperada por los malagueños: el inicio de los muelles, cuya primera piedra se ponía en enero de $1588^{6}$.

Las obras prosiguieron con desigual intensidad en los años siguientes llegando el fondeadero a comienzos del Dieciocho en un lamentable estado, ya que contaba solamente con un muelle llamado viejo en la zona de levante, a los pies de Gibralfaro, padeciendo además una acuciante falta de profundidad en el interior del recinto como consecuencia del levantamiento de los fondos marinos.

La llegada a España de Felipe $V$ y subsiguiente guerra de Sucesión impidió que los trabajos continuasen hasta 1717, año en el que un ingeniero de origen flamenco llamado Bartolomé Thurus ideó un puerto cerrado, consistente en alargar el dique existente curvándolo y enfrentándolo a un nuevo muelle que habría de construirse en la zona de poniente?

Sustituido Thurus por el marqués de Verbom en la dirección de los trabajos a la muerte del primero, las obras públicas malacitanas experimentaron un enorme desarrollo al aprobar Felipe $V$ el proyecto de este último en 1726. El citado ingeniero ideó un puerto abierto prolongando el muelle de levante pero dejando el de poniente en el estado en el que se hallaba en esa fecha, con la finalidad de que las arenas de aluvión del Guadalmedina (verdadero causante del problema según ellos) saliesen del interior del recinto gracias a la acción de las mareas y corrientes ${ }^{8}$. La documentación municipal sobre el particular es extremadamente abundante en esos años, especialmente en lo que se refiere a la política impositiva de la obra, cuya trascendencia era definitiva para la evolución de la misma ${ }^{9}$.

5 Cabrera Pablos, F. R. y Olmedo Checa, M., El puerto de Málaga: 30 siglos de vida 400 años de historia. Málaga, Ed. Junta del Puerto de Málaga, 1988.

* Archivo Municipal de Málaga (AMM), Colección de Originales, libro 8, fols. 175 y siguientes; 242 y siguientes. Véase a Rodríguez Alemán, 1., El puerto de Málaga bajo los Austrias. Málaga, Ed. Diputación Provincial de Málaga, 1984.

7 AMM, Colección de Originales, libro 34, fols. 230-234v; 571-573v; 579-587; 709-714; 721 724v; libro 35, fols. 44-45v. Véase a Cabrera Pablos, F. R., El puerto de Málaga a comienzos del siglo xvIlı. Málaga, Ed. Universidad de inálaga, 1986.

${ }^{8}$ Archivo General de Simancas (AGS), Guerra Moderna, leg. 3.592. Véase a PÉrEz dE CoLosía, M. ${ }^{a}$ I., "Los ingenieros militares y el puerto de Málaga. El informe de Jorge Próspero Verbom", en Ciudad y Mar en la Edad Moderna. Actas del I Congreso Histórico, Cartagena, (prensa).

9 AMM, Actas Capitulares, libro 122, fols. 230-231v, 243-246v; libro 122, fols. 101v-102, etc. 
El proyecto prosiguió con una cierta intensidad hasta que el 1738 el ingeniero director del puerto por esas fechas, Juan Martín Zermeño, se hizo eco de un problema tradicional en estas instalaciones: la falta de profundidad producida por los materiales de arrastre que seguían penetrando en el interior del recinto haciendo muy difícil el tráfico portuario. Tras numerosos trámites, Felipe $V$ autorizó prolongar nuevamente el dique viejo en dirección suroeste a la búsqueda de una mayor profundidad, si bien conservaba la idea básica que sobre los muelles proyectara años antes el marqués de Verbom ${ }^{10}$.

Durante las décadas siguientes, las instalaciones fueron deteriorándose progresivamente a pesar de las denuncias de algunos directores que, como las de Pedro García de Aguilar y Betancourt, no encontraron demasiado eco en la Corte.

Hubo que esperar a la década de los ochenta para que dos nuevos proyectos vinieran a impulsar el desarrollo portuario. Nos estamos refiriendo a los de los ingenieros Julián Sánchez Bort y Joaquín de Villanova en los cuales nos detenemos brevemente ${ }^{11}$.

El primero de ellos consideraba al Guadalmedina auténtico culpable - aunque no el único-, de los problemas que se derivaban de la falta de fondos, aconsejando durante su estancia en Málaga en 1784 el desvío del citado río y la continuación del muelle de poniente en una media luna, ya que la responsabilidad del dique en la penetración de arenas y basuras era en su opinión igualmente manifiesta ${ }^{12}$.

El segundo fue comisionado también por esos años bajo mandato real a realizar un estudio sobre el estado y posible evolución de esta dársena, lo cual realizó y envió a la Corona bajo el título de: «Discurso sobre la prolongación de los muelles del Puerto de la Plaza de Málaga y libertarla de las inundaciones del torrente Guadalmedina, corrigiendo sus deposiciones 'que' de orden de S.M. produjo el Coronel e Ingeniero en jefe D. Joaquín de Villanova" ${ }^{13}$. Para él resultaba mucho más trascendente la acción de las corrientes marinas sobre el muelle de levante, originando la playa de la Caleta, que la influencia del Guadalmedina en el interior de fondeadero. Pensaba, no sin cierta lógica, que una vez que el playazo

AGS, Guerra Moderna, leg. 3.592 y 4.716.

11 Archivo Naval del Viso del Marqués. Sección de Expedientes, Expediente Personal de D. Julián Sánchez Bort. AGS, Sección de Marina, leg. 386.

12 Todas estas construcciones han sido tratadas por Morales Folguera, J. M., «Historia de las obras públicas en Málaga en el siglo xVIII (1) y (II)", Jábega, núm. 50, (1985), págs. 59-80

13 SHM, Colección Aparici, siglo xvill. 
de la Caleta hubiera aumentado en superficie alcanzando el morro de levante, los materiales arrastrados por las corrientes marinas a las que antes nos referíamos cerrarian la bocana del puerto impidiendo, o al menos dificultando, el tráfico marítimo.

Carlos III decidió finalmente acometer las obras proyectadas por Sánchez Bort sobre el río Guadalmedina consistentes en ahondar el lecho del río, levantando al mismo tiempo unos murallones de suficiente altura a su paso por la ciudad como para impedir los desbordamientos. La muerte del monarca en 1788 impidió actuar sobre las instalaciones portuarias una vez solucionados, al menos temporalmente, los arrastres de arenas de aluvión del carcano riachuelo.

El final de la centuria sorprendió al puerto de Málaga casi con los mismos problemas que padecía desde su inicio, a pesar de las cuantiosas sumas que hasta ese momento se habian gastado en su construcción. Se hizo un nuevo embarcadero en el muelle de poniente a partir de 1784 bajo la dirección de Villanova y las fortificaciones experimentaron algunas reformas en los últimos años de dicho siglo.

La llegada del Diecinueve y el aumento del tráfico comercial que experimentó Málaga en ese tiempo obligó a nuevas ampliaciones mucho más ambiciosas, que como las de los ingenieros R. Yagüe, F. Prieto y J. Valcarce dieron a los muelles malacitanos en lo fundamental la fisonomía característica que hoy nos presentan.

\section{EL GUADALMEDINA}

Uno de los capítulos más importantes en el estudio de las obras públicas malagueñas en el análisis de los sucesivos proyectos que se realizaron a lo largo de los últimos cuatro siglos para acabar con la permanente amenaza de las inundaciones del río Guadalmedina, que periódicamente asolaban a esta ciudad.

Parece fuera de toda duda que los problemas con el citado riachuelo comenzaron cuando su álveo se fue levantando poco a poco tras la indiscriminada tala de árboles que experimentó su cuenca a finales del siglo xv y en la primera mitad del xvI, si bien es cierto que la responsabilidad en las temidas riadas en el interior de la urbe las comparte dicho río con los arroyos de Barcenillas, la Manía, Calvario y Olletas, los cuales recogiendo el agua de los montes cercanos la dirigían hacia calle de la 
Victoria y Carretería, en donde uniéndose con las del Guadalmedina producian tragedias fáciles de imaginar ${ }^{14}$.

Durante el siglo XVIII también padecieron los ciudadanos los mismos problemas que en el período antecedente y las soluciones que entonces se ofrecieron fueron igualmente semejantes: desviar el río antes de entrar en Málaga hacia poniente o levante 0 , en el caso de que tal proyecto no fuera posible por problemas técnicos y económicos, levantar unos paredones a lo largo del recorrido urbano evitando así la inundación de la ciudad ${ }^{15}$.

El estudio documental nos revela que el desvío nunca fue tenido en cuenta en la Corte por la elevada cuantía de su ejecución, a pesar de las sugerencias de los ingenieros que trabajaron en estas obras. Respecto a los muraliones, en esta centuria se construyeron parcialmente y en determinadas zonas para proteger los lugares más bajos y por lo tanto más desprotegidos ${ }^{16}$, utilizándose en muchos casos el recurso más barato de arar el álveo del río para rebajarle, prohibiendo al mismo tiempo sembrar en sus márgenes en un intento de evitar que la labor de la azada removiese una tierra que después sería arrastrada por las aguas de lluvia, levantando el lecho del Guadalmedina y propiciando los desbordamientos ${ }^{17}$.

Las inundaciones fueron numerosísimas a lo largo de la centuria, destacando sobre todo la de 1764 que produjo importantes destrozos en la ciudad, según consta en los informes que se dirigieron a la Corte y en las noticias recogidas en la propia documentación municipal ${ }^{18}$.

Con el motivo anterior se encargaron sendos proyectos a los técnicos de más prestigio en aquellos momentos como lo eran A. Ramos y F. Pérez. Presentados ambos al ingeniero director de las Reales Obras de Málaga José Crane, en el mes de septiembre de ese año elaboró un informe que dirigió al Ayuntamiento, en el que abundaba en lo expuesto por Ramos

14 Cabrera Pablos, F. R. y Olmedo Checa, M., op. cit., véase el capítulo dedicado al Guadalmedina.

15 Pérez de Colosía, M. ${ }^{2}$ I., “El Guadalmedina en el sigloxvill», Baetica, núm. 5, (1982), págs. $171-194$.

16 AMM, Actas Capitulares, libro 128, fols, 584v-585, 627-628; libro 132, fols. 445v-446, $489 \mathrm{v}$.; 137, fols. $475 \mathrm{r}$ y $\mathrm{v}$. Son éstos unos ejemplos entre muchos de los intentos de construir paredones en las zonas más bajas, a veces aprovechando incluso la construcción de una casa o la reforma de un muro.

17 García de la Leña, C., Conversaciones Históricas Malagueñas. Málaga, Ed. Caja de Ahorros Provincial de Málaga, 1981.

18 AMM, Actas Capitulares, libro 154, fols. 263v-264v. 
sobre el desvío del cauce hacia la zona de poniente, ofreciendo sus propias opiniones al respecto. El importe estimado era algo más de siete millones de reales según consta en el mencionado escrito y resalta la urbanización que se podría realizar en. el lecho del rio con plantación de árboles y construcción de plazas, to cual le convierte un auténtico proyecto ilustrado de los que con tanta profusión se realizaron durante ese siglo ${ }^{19}$.

Los mismos informes de Villanova y Sánchez Bort sobre el puerto de Málaga, a los que nos referíamos anteriormente, contienen importantes manifestaciones sobre el Guadalmedina que hacen obligada su consulta para cualquier trabajo en profundidad sobre una obra de extraordinaria importancia en la economía de la ciudad y la seguridad de sus moradores, a la que nunca se le prestó desde la Corte la atención deseada ${ }^{20}$.

La propia densidad e interés de la documentación existente en el Archivo Municipal de Málaga demuestra que raro es el año en el que entre los meses de septiembre y noviembre no aparecen interesantes datos en un sentido u otro sobre un río cuyo tratamiento detenido resulta aquí imposible por falta de espacio.

\section{EL ABASTECIMIENTO DE AGUA}

Málaga fue siempre una ciudad deficitaria en tan necesario elemento y si en los tiempos más remotos las aguas del Guadalmedina Ilegaban limpias y regulares a la ciudad siendo por lo tanto susceptibles de ser utilizadas en el abastecimiento público, con el paso de los años se volvieron subálveas por las razones ya apuntadas y obligaron a las autoridades a buscar la forma de aumentar el caudal con otros manantiales más o menos cercanos.

Pasando por alto los de la Culebra y Almendral del Rey, cuyo estudio ya fue en su día realizado por el investigador malagueño Manuel Olmedo con el magisterio que le es habitual ${ }^{21}$, el recurso más abundante en el siglo xvIII se detectó en la falda de la sierra de Mijas, en un lugar próximo

19 Ibidem, libro 155 , fols. $307 v$ y sigulentes.

20 El capítulo de los puentes ocupó también importantes páginas de nuestra historia. Véase Molina Cobos, A., Descripción de seis puentes de Málaga. Madrid, Ed. Colegio de Caminos, Canales y Puertos, 1987.

21 Olmedo ChecA, M., "Las aguas de la Trinidad: manantiales de la Culebra y del Almendral del Rey", Jábega, núm. 48 (1984), págs. 28-40. 
a Churriana conocido como Fuente del Rey. De su análisis nos ocupamos brevemente.

Hacia 1720 la escasez de agua en la ciudad se hizo tan acuciante que la gente veíase obligaba a beber en los meses del estío de pozos salobres con el evidente riesgo que semejante práctica entrañaba para la salud pública.

Las autoridades encargaron entonces a Bartolomé Thurus y a otros técnicos en la materia que buscasen nuevos yacimientos, entre los que sin duda alguna según los citados el que ofrecía más garantía era el de la Fuente del Rey al que anteriormente nos referíamos. Su dictamen fue favorable junto a otros especialistas que, como Felipe Pérez y fray Miguel de los Santos, sugerían igualmente una obra que sin duda alguna redundaría en beneficio de todos ${ }^{22}$.

El proyecto fue encomendado al arquitecto Toribio Martínez de la Vega, quien levantó los planos de un acueducto y un puente que, cruzando el Guadalhorce, sirviera a la vez de comunicación de la ciudad con los pueblos de la zona ${ }^{23}$.

Durante todo el Dieciocho las obras fueron poco a poco languideciendo después del empuje inicial, paralizándose totalmente los trabajos en 1733 por el enfrentamiento que tuvo lugar entre el propio Concejo y la Corona a propósito de la dirección del proyecto tras la muerte de Martínez de la Vega sucedida años antes. La documentación municipal es extremadamente abundante en este período sobre las reclamaciones presentadas y la evolución de los acontecimientos.

Hubo aún algunos conatos de continuación como el que tuvo lugar en 1757, en el que las modificaciones que experimentaron puente y acueducto fueron de índole menor, a pesar de que los datos continúan esporádicamente acudiendo a los libros de actas capitulares del Ayuntamiento de Málaga por muy diferentes motivos ${ }^{24}$.

El proyecto de puente sobre el Guadalhorce permaneció todavía durante años ocupando la atenciór: de los malagueños, mientras que el

22 La cartografía imprescindible para el estudio de tan importante obra pública se encuentra repartida básicamente entre el Servicio Geográfico del Ejército y el Archivo Histórico Nacional. Remitimos igualmente a CABrera PABlos, F. R., El puerto de Málaga a comienzos del siglo xVIII. Málaga, Ed. Universidad de Málaga, 1986, págs. 346-364.

23 Archivo Histórico Nacional, Sección de Consejos, leg. 45 y AGS, Secretaría de Hacienda, leg. 1.478. Véase a Cabrera Pablos, F. R., "La Fuente del Rey: documentos para su estudio», Jábega, núm. 57, (1987), págs. 38-47.

24 AMM, Actas Capitulares, libro 148, fols. 207; libro 157, fols. $380 \mathrm{v}-381$ 
abastecimiento de agua quedó poco a poco en el olvido utilizándose lo hecho hasta ese momento para el regadío de algunas huertas particulares de aquella zona. Lamentable final para un proyecto en el que tantos esfuerzos y dineros se habían gastado a lo largo de más de medio siglo, sin que el interés que mostrara en su inicio un gobernador de la talla de Gerónimo de Solís y Gante pudiera verse continuado en sus sucesores, los cuales se despreocuparon absolutamente de esta obra.

Por lo tanto, fue preciso buscar otros manantiales y así se hizo, esta vez en la zona norte de la ciudad con un resultado más que satisfactorio. Tras los estudios pertinentes empezaron las nivelaciones del terreno y el numeroso trazado de puentes y molinos. A partir de 1784, tal y como nos cuenta la autorizada pluma de la profesora Rosario Camacho, «Málaga bebía las aguas del Guadalmedina que llegaban a la ciudad mediante el acueducto que había costeado el ilustrado obispo Molina Lario y cuya obra dirigió el arquitecto J. Martín de Aldehuela» ${ }^{25}$.

Un completo expediente conservado en el archivo de la Sociedad Económica de Amigos del País nos da cuenta de todo lo referente a tan importante proyecto: "Relación de la obra del Acueducto de Málaga, al Rey Nuestro Señor, por Don Ramón Vicente y Monzón, Arcediano de Ronda, Dignidad y Canónigo de la Santa Iglesia de dicha Ciudad».

De esta forma y a lo largo de varios kilómetros, el agua corría hasta Málaga procedente de la parte alta del Guadalmedina moviendo varios molinos y sirviendo durante muchos años para el abastecimiento público y de las zonas rurales que encontraba a su paso. Desgraciadamente, el agresivo urbanismo de las últimas décadas de nuestro propio siglo amenaza con destruir por completo una muestra de la historia malagueña, tan importante como ésta y que aparece ya extremedamente deteriorada.

\section{LAS COMUNICACIONES}

La comunicación de la ciudad malacitana con las localidades vecinas tenía en lo fundamental un triple trazado: hacia el este en el denominado camino de Vélez; en dirección contraria, hacia Torremolinos; y el que nos unía con Antequera.

El primero de los citados reflejaba una elevada importancia comercial por depender de su buen estado la fluidez del comercio de la pasa y el

25 Camacho Martinez, R., "Viaje de agua, camino de pan: La fuente y puente de rey en Churriana (Málaga)», Boletín de Arte, núm. 8, (1987), págs. 61-82. 
vino que, procedente de la Axarquía, se embarcaba por nuestro puerto. De esta forma, periódicamente asistimos a una relación epistolar entre este Concejo y el de la localidad de Vélez Málaga, con la finalidad de arreglar los destrozos que el tiempo producía en tan frecuentada vía de comunicación, cada uno en la jurisdicción de su respectivo municipio ${ }^{26}$.

La ruta de Torremolinos, Marbella y Estepona recorría en buena parte los terrenos cercanos a la costa, no encontrándose desde el punto de vista orográfico dificultades dignas de mención, si bien también el Ayuntamiento malacitano recoge diferentes noticias sobre sus reparaciones y mantenimiento ${ }^{27}$.

Respecto a la comunicación entre Málaga y Antequera, hemos encontrado las primeras noticias en el cabildo celebrado el 7 de enero de 1729 , en el cual se recibió una orden de Madrid con las diligencias que habrían de realizarse para iniciar una nueva ruta hacia el interior por la localidad de Colmenar ${ }^{28}$.

Periódicamente, este asunto asomará a las actas de nuestro Ayuntamiento al igual que en la documentación oficial que llega desde la Corte. Así, por ejemplo, en junio de 1782, una carta de Floridablanca anunciaba la decisión real de que el arbitrio hasta entonces destinado a la continuación de la Catedra! malagueña:

"Que todo su producto se emplee en la obra del camino de la expresada ciudad de Málaga a la de Antequera hasta su conclusión, y después de terminada ésta se emplee en concluir lo que reste que hacer en el camino desde la misma ciudad a la de Vélez y Granada...» ${ }^{29}$.

Pocos años más tarde el mismo Floridablanca volvía a recordar a la ciudad la importancia de la ruta por Colmenar, obligándole a pagar 200.000 reales que se había comprometido a entregar para sufragar los gastos y que aún no había hecho efectivos ${ }^{30}$.

En 1832, un diccionario geográfico recordaba sobre este particular que:

25 AMM, Actas Capitulares, libro 158 , fols. $84 \mathrm{r}$ y v; $168 \mathrm{r}$ y v; $184 \mathrm{v}$ y siguientes. El arreglo que acometía la ciudad de Málaga alcanzaba jurisdiccionalmente hasta la torre de Chilches por un valor de 19.000 reales.

27 Ibidem, libro 155, fols. 310v-312. Recoge este documento el estado de los caminos hacia Torremolinos, Churriana y otros.

28 Ibidem, Actas Capitulares, libro 123, fols. 290v-291.

29 AGS, Sección de Marina, leg. 386.

30 AMM, leg. 15, fol. 38-38v. 
"está mandado construir y se trabaja en él... otro hasta Granada por el Colmenar, Alfarnate y Loja, el cual nunca será buen camino por las muchas cuestas que tiene que atravesar, y entre ellas el punto llamado Fuente de la Reina, que está a dos leguas de Málaga y tiene ochocientas varas de altura sobre el nivel del mar» ${ }^{31}$.

En definitiva, las comunicaciones de Málaga hacia el interior nunca fueron buenas y en consecuencia las dificultades que ello entrañaba para el comercio propició que las rutas mercantiles alcanzaran por mar un desarrollo que por tierra resultaba mucho más problemático por las razones apuntadas.

${ }^{31}$ Diccionario Geográfico Universal, vol. 5. Barcelona, imp. J. Torner, 1832, pág. 769. 